\title{
An Experimental Study of the Use of Hydrocarbon MC 22 Refrigerants on Split AC Performance
}

\author{
Jhon A. Wabang ${ }^{1}$, Edwin P.D. Hattu ${ }^{1}$, Jufra D.J Abanat ${ }^{1}$ \\ \{jhonarwabang@gmail.com, edwinhattu10@gmail.com,jufraabanat@gmail.com\} \\ Politeknik Negeri Kupang ${ }^{1}$
}

\begin{abstract}
Air conditioning is a device whose function is to condition the air according to the desired needs. The problem faced so far is that the refrigerant used can have a negative impact on the environment such as the potential for global warming and ozone destruction and disturbing human health. The refrigerant used in this research is the hydrocarbon refrigerant (MC22). The goal is that hydrocarbon refrigerants have the property of being able to lighten compressor work and environmentally friendly. The method used in this research is an experimental method. The test is carried out in stages, namely system vacuuming, refrigerant charging carried out on the basis of the weight of the refrigerant, measurement of system working pressure and performance measurements system and current consumption. The test results show the mass efficiency of the refrigerant and the consumption of electric current respectively $500 \mathrm{gr}$ or $50 \%$ and $6.3 \mathrm{~A}$ or $33 \%$.
\end{abstract}

Keywords: Air Conditioning System, Hydrocarbon (MC 22)

\section{Introduction}

Technological developments in the field of refrigeration systems continue to be a concern because this system is needed in almost all fields, but the refrigerant is one of the causes of damage to the ozone layer and disrupt human health. Ozone-depleting substances (BPO) such as chlorofluorocarbons (CFCs) and hydrochlorofluorocarbons (HCFCs).

In Indonesia, to curb the use of BPO (Ozone Waste), the Minister of Industry issued the Minister of Industry Regulation No. 41 of 2014 and Minister of Commerce Regulations No. 55 of 2014 about the same ban. The regulation states that starting 1 January 2015 HCFC HCFC 22 and HCFC $141 \mathrm{~b}$ types are prohibited from being used in: "Filling in the production process of machines and air conditioners, air conditioning machines, and refrigeration tools / machines, rigid foam production processes for goods freezer, domestic, refrigenerator, boardstock / laminated, refrigenerated trucks, and integral skin production processes for the use of the automitive and furniture sectors. ". Then it was emphasized again that "starting December 1, 2030 HCFCs are prohibited from being used for maintenance of goods".

Today, a number of manufacturers are busy switching to AC technology that is more environmentally friendly. One of them by using Freon R-32. But the problem is the air conditioner or other cooling material that still uses R22 and conditions are still good (proper function) must be destroyed or replaced. Then to replace Freon R22 to Freon R32 is usually constrained by the form of Freon packaging (Freon holder). This is often an obstacle for some companies that want to replace the type of freon found in air conditioners or other cooling machines. 
One of the ingredients that can be used as a cooling agent in an air conditioner system is a hydrocarbon refrigerant (MC 22) [1]. hydrocarbons can increase the value of COP [2]. There is a difference in the performance of air conditioners using refrigerants R22 and R290 in terms of each variation in the total mass of the refrigerator [3],[4]. On the other hand, there are savings in terms of electricity consumption for hydrocarbon refrigerants (R290) [5]. Significant efficiencies occurred in both the COP, electrical energy consumption and work of compressors for R290 gydrocarbon refrigerants [6].

The purpose of using hydrocarbon refrigerant (MC 22) is hydrocarbon refrigerant (MC 22) which has properties that can ease the work of the compressor, so that the use of the AC compressor becomes longer and environmentally friendly, because it does not damage the ozone layer and does not cause Greenhouse / Global Warming Effects. Using Musicool (MC-22) means you can contribute to protecting the environment. The characteristics of this hydrocarbon refrigerant (MC 22) then in this study the analysis was performed on the performance of Split AC using a hydrocarbon refrigerant (MC 22). Performance reviews include the amount of refrigerant mass used and the consumption of electric current as well as the effects of refrigeration and the resulting cooling capacity.

\section{Experimental Methodology}

This research was conducted in the Refrigeration Engineering laboratory, with the set up as follows:

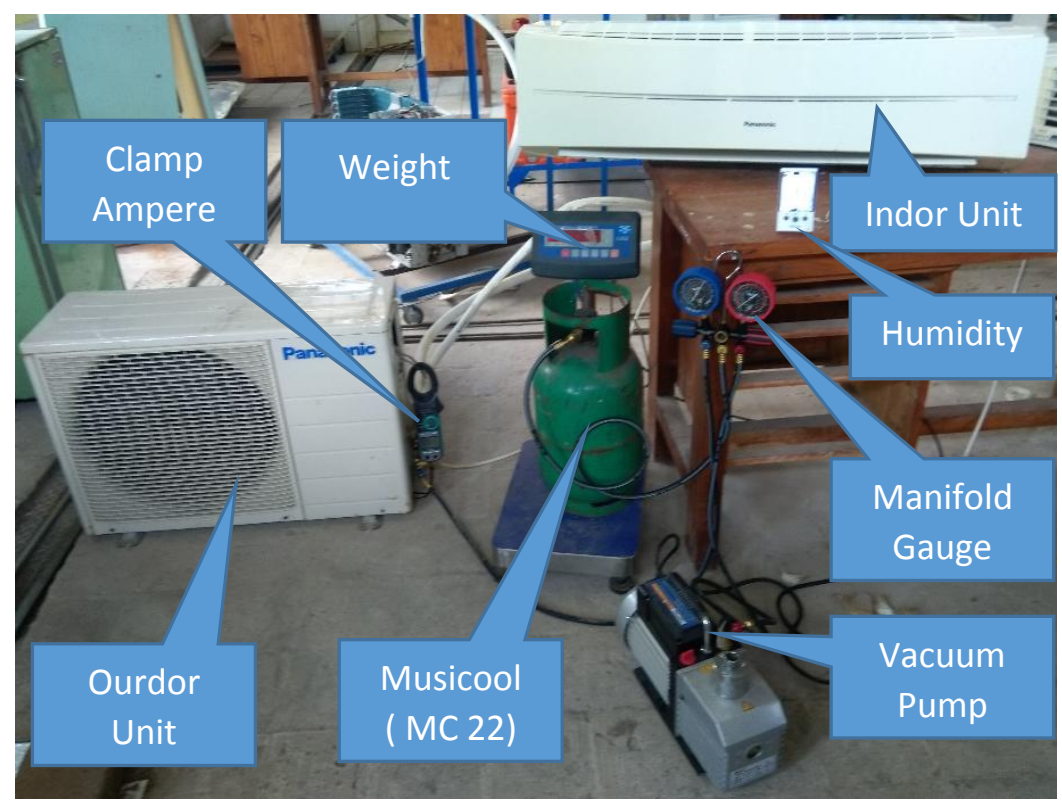

Fig. 1. Set Up Experimental 
From this set up of experiments, a system test is performed with steps such as the following flow chart:

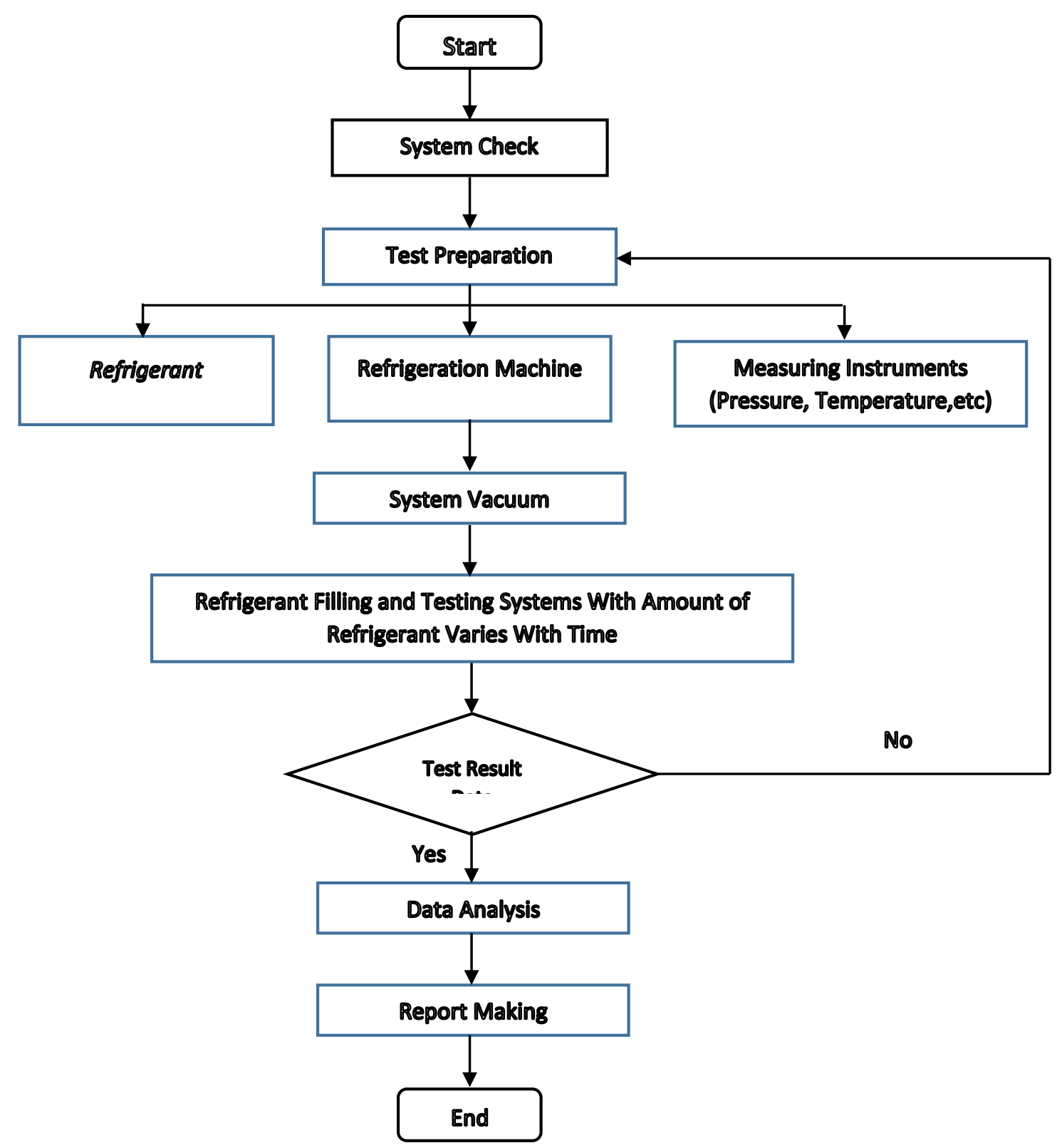

Fig. 2. Flow Chart Diagram 


\section{Results and Discusion}

This test is carried out on a split $\mathrm{AC}$ with the following specifications:

1. The mass of refrigerant

$$
=1000 \mathrm{gr}
$$

2. Electric current $=9.8-10 \mathrm{~A}$

3. Cooling capacity $=5.28 \mathrm{~kW}$

Based on the planned system design and the research flow, the tests are carried out and the results obtained are presented as in the following table:

Table 1. Testing Results Data

\begin{tabular}{|c|c|c|c|c|c|c|c|c|c|c|c|c|}
\hline \multirow{2}{*}{ No } & \multirow{2}{*}{$\begin{array}{l}\text { Time } \\
\text { (Menit) }\end{array}$} & \multirow{2}{*}{$\begin{array}{c}\text { Mass } \\
\text { Refrigerant } \\
\quad \text { (gr) }\end{array}$} & \multicolumn{5}{|c|}{ Temperature $\left({ }^{0} \mathrm{C}\right)$} & \multirow{2}{*}{$\begin{array}{c}\text { Humidity } \\
(\%)\end{array}$} & \multirow{2}{*}{$\begin{array}{l}\text { Wind Speed } \\
\qquad(\mathbf{m} / \mathbf{s})\end{array}$} & \multirow{2}{*}{$\begin{array}{c}\text { Low } \\
\text { Pressure } \\
\text { (psi) }\end{array}$} & \multirow{2}{*}{$\begin{array}{l}\text { Voltage } \\
\text { (V) }\end{array}$} & \multirow{2}{*}{$\begin{array}{l}\text { Electrical } \\
\text { (A) }\end{array}$} \\
\hline & & & $\begin{array}{c}\text { Dry } \\
\text { Bulb } \\
\end{array}$ & $\begin{array}{c}\text { Wet } \\
\text { Bulb }\end{array}$ & Evaporator & Condenser & Enviromental & & & & & \\
\hline 1 & 30 & 100 & 23 & 26 & 22,8 & 30 & 29,1 & 47 & 4,78 & 7,5 & 218,5 & 4,9 \\
\hline 2 & 30 & 200 & 20 & 19 & 18,2 & 32 & 29,1 & 43 & 4,56 & 30 & 217,2 & 5,7 \\
\hline 3 & 30 & 300 & 17 & 16 & 13 & 32 & 29,1 & 40 & 4,12 & 55 & 216,3 & 6,3 \\
\hline 4 & 30 & 400 & 15 & 12 & 10,3 & 32,1 & 29,1 & 39 & 4,16 & 63 & 215,1 & 6,5 \\
\hline 5 & 30 & 500 & 14,5 & 13 & 10,1 & 31,8 & 29,1 & 37 & 3,92 & 64 & 216,5 & 6,3 \\
\hline 6 & 30 & 600 & 14,5 & 13 & 10,1 & 31,8 & 29,1 & 37 & 4,21 & 65 & 216,7 & 6,3 \\
\hline 7 & 30 & 700 & 14,5 & 13 & 10,1 & 31,8 & 29,1 & 37 & 4,21 & 65 & 216,7 & 6,3 \\
\hline 8 & 30 & 800 & 14,5 & 13 & 10,1 & 31,8 & 29,1 & 37 & 4,21 & 65 & 216,7 & 6,3 \\
\hline 9 & 30 & 900 & 14,5 & 13 & 10,1 & 31,8 & 29,1 & 37 & 4,21 & 65 & 216,7 & 6,3 \\
\hline 10 & 30 & 1000 & 14,5 & 13 & 10,1 & 31,8 & 29,1 & 37 & 4,21 & 65 & 216,7 & 6,3 \\
\hline
\end{tabular}

The test results in the table above can be calculated the performance of split AC with MC 22 refrigerant as follows:

a. Amount of Mass of Refrigerant vs. Evaporator Temperature

The amount of mass of refrigerant entered in this system, after reaching 500gr, the evaporator temperature becomes stable at $10,1^{0} \mathrm{C}$. This shows that there is no need for the addition of refrigerant anymore because the work of the compressor is at its maximum and the recommended temperature as the specification of this split $\mathrm{AC}$ is $10,1^{\circ} \mathrm{C}$. If it is added does not give the effect of refrigeration on the air conditioner and the room, but it has a bad effect on the composer because the compressor workload is getting bigger. The relationship graph of the Mass Amount of Refrigerant vs. Evaporator Temperature as shown in Figure 3. 


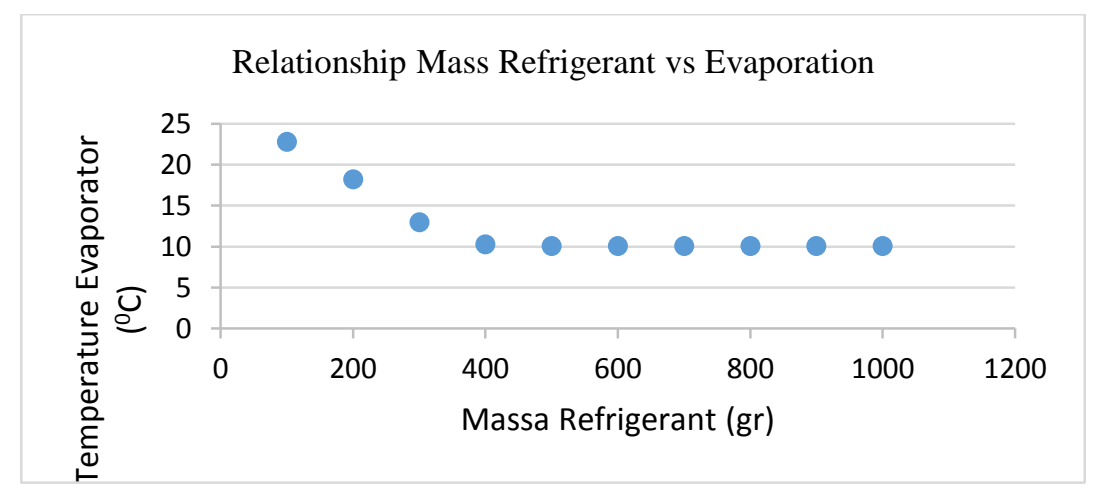

Fig. 3. Graph Relationship amount of refrigerant mass vs Evaporator Temperature

b. The Amount of Mass of Refrigerant vs Electric Current Consumption

The amount of mass of refrigerant greatly affects electricity consumption. Based on the specifications of this split $\mathrm{AC}$, to reach the evaporator temperature of $10,1^{\circ} \mathrm{C}$, the mass required is $1000 \mathrm{gr}$ with electricity consumption of $9.8 \mathrm{~A}-10 \mathrm{~A}$. But by using MC 22 refrigerant, to reach a temperature of $10,1^{\circ} \mathrm{C}$, the required mass is $500 \mathrm{gr}$ with an electric current consumption of $6.3 \mathrm{~A}$, or an efficient amount of refrigerant mass and an electric current consumption of $50 \%$ and $36 \%$, respectively. For the cooling capacity is close to the specifications of $5.18 \mathrm{~kW}$. The relationship between refrigerant mass vs. electricity consumption can be seen in Figure 4 below.

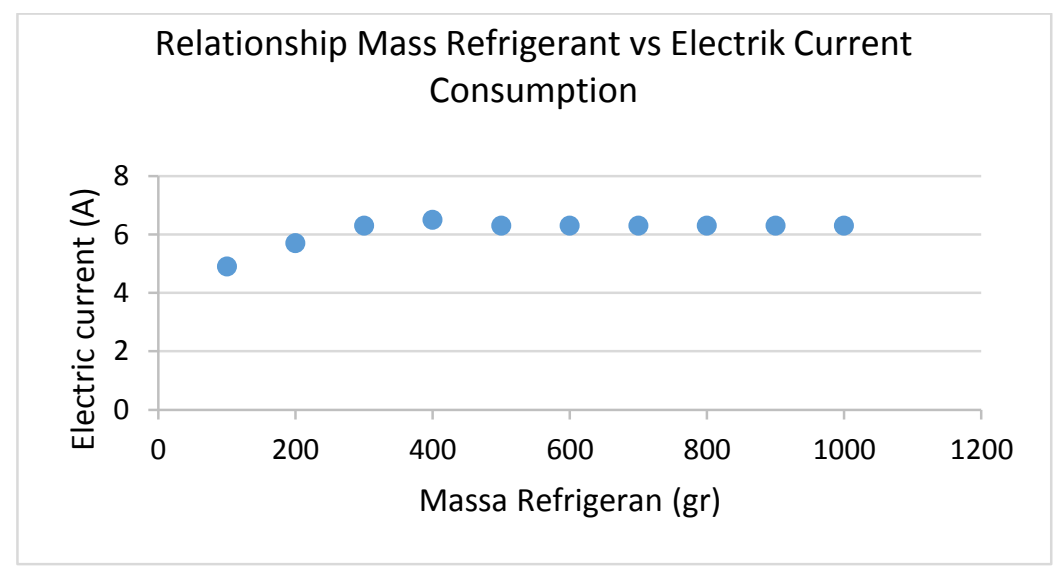

Fig. 4. Graph Relationship Mass Refrigerant (gr) vs Electrik Current (A) Consumption 
c. Based on the test data used in the coolpack software, the following data are obtained:

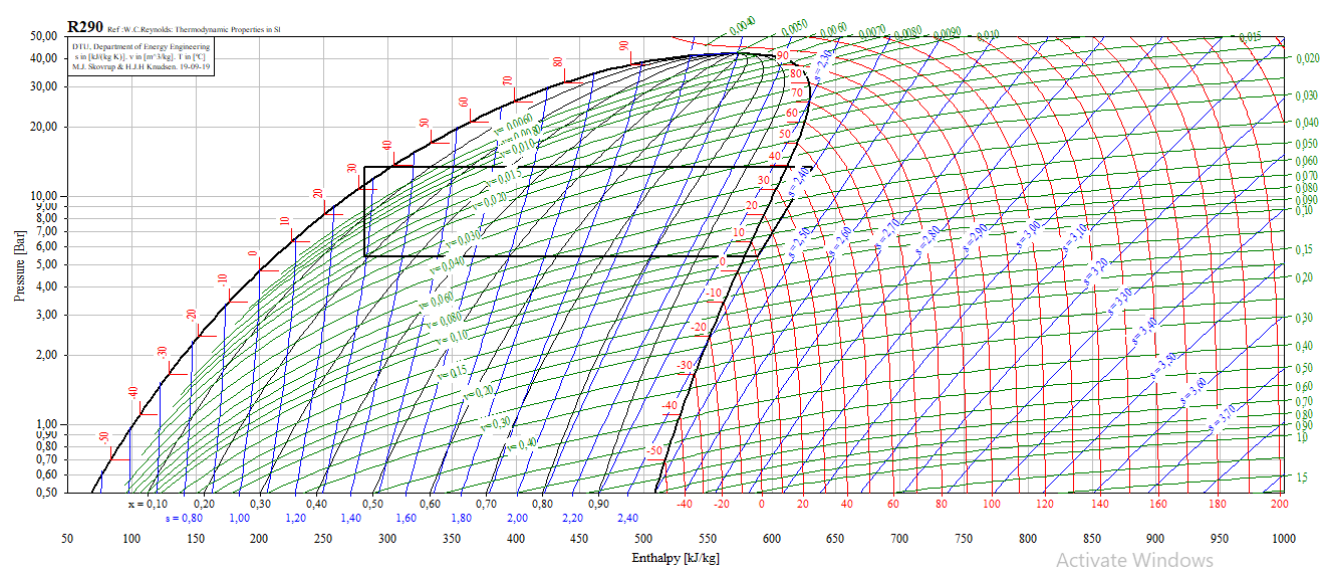

Fig. 5. Graph of p-h diagram for R290

Figure 5 can be used to determine AC Split performance as follows:
$\mathrm{h}_{1}=588,49 \mathrm{~kJ} / \mathrm{kg}$
$\mathrm{h}_{2}=632,38 \mathrm{~kJ} / \mathrm{kg}$
$\mathrm{h}_{3}=283,58 \mathrm{~kJ} / \mathrm{kg}$
$\mathrm{h}_{4}=283,58 \mathrm{~kJ} / \mathrm{kg}$

1. Specific work by the Compressor $\left(\mathrm{Q}_{\mathrm{w}}\right)$. $43,89 \mathrm{~kJ} / \mathrm{kg}$

2. The heat is released by the condenser $\left(q_{k}\right)$ $348,8 \mathrm{~kJ} / \mathrm{kg}$

3. Refrigeration Effect $\left(\mathrm{q}_{\mathrm{e}}\right)$ $304,91 \mathrm{~kJ} / \mathrm{kg}$

4. Coeffisient Of Performance(COP)

a. $\mathrm{COP}_{\text {aktual }}=6,95$

b. $\mathrm{COP}_{\text {carnot }}=9,43$

5. Refrigeration Efficiency $(\eta)$ 73,70\%

6. Cooling Capacity $\left(\mathrm{Q}_{\mathrm{e}}\right)$ $5,18 \mathrm{~kW}$.

\section{Conclusion}

The use of MC22 on split AC R22, obtained the mass efficiency used and electricity consumption by $50 \%$ and $36 \%$ respectively, while the cooling capacity is $5.2 \mathrm{~kW}$. This capacity value is close to the specification capacity of $5.8 \mathrm{~kW}$. This shows that by using MC 22 efficiency occurs both the mass of the refrigerant and the consumption of sufficient electrical current, resulting in savings in using hydrocarbon refrigerant material. The resulting Coefficient Of Performance (COP) is also quite large at 6.95. 


\section{Acknowledgements}

The authors would like to thank State Politeknik of Kupang for the financial support through the RUTIN Research Programme. A thank you also goes to Wilmar for their help to record the values of performance of AC split parameters using manifold gauge and electrical equipments.

\section{Reference}

[1] Comparative Analysis of Performance of 2HP Capacity Air Conditioner Coolers Using R22, R290 and R407C Refrigerants, Mahendra, Journal of Educational Technology and Air Condition Sekayu Polytechnic (PETRA), Volum 1, No.1. August 2015, h 11-19, ISSN-P 24608408.

[2] Comparison of Miniature Skating System Performance Using R22 and R290 (Hydrocarbon) Refrigerants, Ismail Willid, Proceedings of the National Industrial and Information Technology Engineering XIII 2018 (ReTII), November 2018, pp.286-292, ISSN 1907-5995.

[3] Experimental Study of the Effect of Changing Variations in Refrigerant-22 with Musicool22 in Air Conditioning Systems with Pre-cooling, 2016, Arnovia Sebastiana, ITS Engineering Journal Vol.5, No.2, 2016, ISSN : 2337-3539.

[4] Analysis of Effect of Mass Amount of MC-22 Hydrocarbon Refrigerant on Cooling Engine Performance, Nurhadi, 2010, National Seminar of Master and Doctoral Programs of the Faculty of Engineering UB (SN-PMD-FTUB) ke-Malang 8 December 2010.

[5] Analysis of the Use of Electric Energy and COP on 900 watt AC Split Using MC 22 and R22 Hydrocarbon Refrigerants, Harsono, Indonesian Mechanical Engineering Journal, Vol.12 No.1 (April 2017) Page. 25-28.

[6]Musicool-22 Efficiency with Retrofit Process on AC Daikin 3 PK Brand, Khoeri, Department of Electrical Engineering, Muhammadiyah University, Semarang, Journal of Electrical Media, Vol.10 No.1 June 2017 